\title{
SAFARI DAKWAH SEBAGAI MEDIA PEMBENTUKAN KARAKTER BAGI OSIS MTS AL YAKIN PUNGPUNGAN
}

\author{
Sahri \\ Universitas Nahdlatul Ulama Sunan Giri Bojonegoro \\ sahriunugiri@gmail.com \\ Moh. Miftahul Choiri \\ Universitas Nahdlatul Ulama Sunan Giri Bojonegoro \\ choirinafik90@gmail.com
}

\begin{abstract}
Abstrak
Artikel ini mengkaji tentang tradisi Safari Dakwah sebagai media pembentukan karakter bagi OSIS MTs Al-Yakin Pungpungan. Safari Dakwah ialah kegiatan dakwah keliling dari rumah ke rumah para anggota OSIS yang diadakan setiap dua minggu sekali. Kegiatan ini merupakan salah satu agenda rutin yang dilaksanakan oleh anggota OSIS beserta guru pendamping. Tidak lain tujuannya ialah untuk pembekalan karakter para anggota OSIS. Misalnya dengan menumbuhkan jiwa kepemimpinan, lalu kemudian kedisiplinan, taat pada peraturan dan sebagainya. Kegiatan ini pada awalnya adalah gagasan atau ide dari kepala sekolah, para guru dan seluruh warga sekolah. Berawal dari ide, lalu kemudian diterapkan dan berjalan sampai sekarang dengan baik. Tentu kegiatan yang sudah berjalan ini setiap saat dievaluasi, dipilih kegiatan-kegiatan yang ada kaitannya dengan penumbuhan karakter anak. Isi kegiatan tersebut ialah pembacaan doa-doa dan ceramah agama yang pembicaranya diambil dari siswa secara bergantian. Harapannya semoga kegiatan Safari Dakwah dapat dilaksanakan terus secara konsisten pada MTs Al Yakin atau bahkan pada M'Ts yang lain.
\end{abstract}

Nazhruna: Jurnal Pendidikan Islam

Vol. 1 No 2 Agustus 2018. Issn: 2614-8013. Hal. 223-240 
Kata Kunci: Safari Dakwah, Karakter, OSIS

\begin{abstract}
This article examines the tradition of Safari $D a^{\prime} w a h$ as a character formation medium for OSIS MTs Al-Yakin Pungpungan. Safari Da'wah is a da'wah activity going from house to house members of the OSIS held every two weeks. This activity is one of the routine agenda undertaken by members of OSIS and accompanying teachers. No other purpose is to brief the character of the members of OSIS. For example by growing the soul of leadership, and then discipline, obey the rules and so forth. This activity was originally the idea of the principal, the teachers and the entire school community. Starting from idea, then applied and running until now well. This activity is evaluated at all times, selected activities that are related to the growth of children's character. The content of these activities is the reading of prayers and religious speech that speakers are taken from students in turn. Hopefully this Safari Dakwah activities can be carried out consistently on MTs Al Yakin or on other MTs.
\end{abstract}

Keyword: Safari Da'wah, Character Building, OSIS

\title{
Pendahuluan
}

Akhir-akhir ini manusia banyak yang sikapnya menyimpang dari rel yang sudah ditentukan, baik nilai-nilai, kebudayaan, moral serta agama. Sebagai bukti banyak terjadi pertengkaran antar genk, tindak kekerasan, perilaku pergaulan bebas, tawuran atau yang lainnya. ${ }^{1}$ Padahal Manusia merupakan Makhluk ciptaan Allah yang paling mulia dari pada makhluk yang lainnya. Manusia tidak akan pernah mampu hidup sendirian, karena pasti membutuhkan yang namanya keluarga, teman, dan lain sebagainya. Dengan keluarga, teman dan masyarakat itulah akan terbentuk sebuah pengalaman dan pendidikan. Keluarga memiliki salah satu tugas dan peran penting dalam kehidupan serta harus mampu membekali nilai-nilai kehidupan yang dibutuhkan oleh anak. ${ }^{2}$ Secara tidak langsung bahwasannya manusia membutuhkan yang namanya pendidikan. Manusia dilahirkan dalam posisi tidak

1 Rosidatun, Model implemntasi pendidikan karakter (Gresik: Caramedia Commucication, 2018), 1.

${ }^{2}$ Huda Faiq Jauharu, 'Nilai-Nilai Pendidikan Akhlak Menurut Al Qur'an Surat at Thagabun Ayat 14' (IAIN Walisongo, 2018), 2. 
mengetahui apa-apa karena semuanya masih membutuhkan proses. Sebagaimana firman Allah:

Artinya: dan Allah mengeluarkan dari perut ibumu dalam keadaan tidak mengetahui sesuatupun, dan Dia member pendengaran, Penglibatan dan hati agar kamu bersyukur (Q.s An Nahl:78)

Melihat penjelasan ayat diatas, tidak ada alasan manusia untuk tidak melaksanakan sebuah pendidikan dan menuntut ilmu. Dengan adanya pendidikan manusia akan menjadi orang yang berguna bahkan akan dihormati karena ilmunya. Pendidikan bagi manusia merupakan sesuatu hal yang sangat dibutuhkan.

Pendidikan merupakan sebuah salah satu aset yang sangat tak ternilai bagi individu dan masyarakat. Karena pendidikan sebagai salah satu proses yang bertujuan untuk mencerdaskan kehidupan bangsa serta mencapai cita-cita dan tujuan ${ }^{3}$. Dengan pendidikan inilah akan tercetak generasi yang mapan dan berguna untuk menghadapi perkembangan zaman. Dengan pendidikan juga akan tercipta suatu kepribadian, perilaku, tingkah laku bahkan sebuah karakter yang melekat dalam diri siswa.

Pendidikan yang diajarkan saat ini bukan pendidikan yang mencerdaskan siswa saja, melainkan pendidikan yang luar biasa yakni pendidikan yang bersifat karakter. Karena pendidikan karakater mampu memberikan sebuah bantuan agar seseorang mampu bertumbuh menjadi insan yang sempurna ${ }^{4}$. Selain pendidikan karakter sebagai penanaman nilai, pendidikan karakter disini berusaha membuat sebuah lingkungan hidup bagi individu untuk menghayati untuk kepentingan masyarakat yang sekaligus memiliki moral yang baik ${ }^{5}$.

3 Syamsu Yusuf and A. Juntika Nurihsan, Landasan Bimbingan \& Konseling (Program Pascasarjana Universitas Pendidikan Indonesia dengan PT Remaja Rosdakarya, 2006), 2.

4 Doni Koesoema A., Pendidikan Karakter (Jakarta: Gramedia Widiasarana Indonesia, 2007), 4.

5 Muhammad Anas Ma`arif, 'Analisis Strategi Pendidikan Karakter Melalui Hukuman Preventif, Ta'allum: Jurnal Pendidikan Islam 6, no. 1 (6 March 2018): 35, https://doi.org/10.21274/taalum.2018.6.1.31-56. 
Sebagai lembaga pendidikan yang baik dan terpercaya oleh masyarakat, sebaiknya dalam lembaga pendidikan harus memunculkan atau menghasilkan sebuah produk yang bagus terhadap siswa. Produk tersebut ialah karakter yang baik. Karena dengan produk dan output yang baik maka dengan sendirinya masyarakat akan berbondongbondong menyekolahkan anaknya di lembaga tersebut. Oleh karena itu, lembaga harus saling bekerjsama dengan orang tua dan masyarakat sekitar ${ }^{6}$. Selain itu juga, sebuah lembaga pendidikan harus memiliki beberapa program atau kegiatan yang jelas dan menyenangkan namun memiliki efek yang sangat baik demi terbentuknya sebuah pendidikan yang berkarakter.

MTs Al Yakin merupakan lembaga pendidikan yang berada di bojonegoro yang melaksanakan sebuah safari dakwah. Safari dakwah disini bertujuan untuk membentuk karakter siswa baik secara jasmani maupun rohani. Dengan adanya safari dakwah disini berusaha dan terus berusaha dalam mengembangkan dan melanjutkan pendidikan yang berkarakter. Akan tetapi, jika program pendidikan karakter yang dilaksanakan oleh MTs Al Yakin tersebut bisa dikatakan berhasil dan efektif haruslah memiliki tolak ukur yang jelas.

Melihat keadaan diatas, kegiatan yang ada di sekolahan harus di optimalkan sebagai bentuk pendidikan karakter anak bangsa. Oleh karena itu, peneliti mengangkat sebuah judul safari dakwah sebagai media pembentukan karakter OSIS MTs Al Yakin Pungpungan.

\section{Metode}

Pada penelitian ini, peneliti menggunakan pendekatan kualitatif. Dikarenakan penelitian ini merupakan penelitian lapangan. sedangkan jenisnya menggunakan pendekatan deskriptif kualitatif. Karena dengan menggunakan jenis pendekatan deskriptif kualitatif akan memperoleh hasil yang real dan nyata serta tidak menggunakan angka.

Dalam penelitian ini, peneliti memperoleh data dari berbagai sumber. Terutama sumber primer yang didalamnya terdiri dari kepala sekolah, guru dan karyawan serta sumber sekunder yang merupakan sumber pendukung untuk membantu peneliti dalam proses penelitian.

${ }^{6}$ Koesoema A., Pendidikan Karakter, 6. 
Dalam proses pengumpulan data, peneliti menggunakan berbagai metode yaitu metode Observasi, Metode Wawancara dan Metode dokumentasi. Dengan menggunakan ketiga metode tersebut peneliti mampu mengumpulkan berbagai macam data yang diperlukan.

Kemudian setelah itu, dalam proses menganalisis sebuah hasil yang sudah ditemukan, dalam penelitian ini menggunakan teori yang sudah diluncurkan oleh Miles dan huberman yaitu: (1) Reduksi data, (2) Display data dan (3) Pengambilan kesimpulan atau sebuah verifikasi ${ }^{7}$

\section{Hasil Penelitian Dan Pembahasan}

\section{Biografi MTs Al Yakin Pungpungan}

\section{Profil MTs Al Yakin Pungpungan}

MTs Al Yakin merupakan salah satu Madrasah yang berada di kecamatan Kalitidu kabupaten Bojonegoro. Tepatnya MTs Al Yakin berada di alamat Jl. Raya Bojonegoro-Cepu No. 223 Desa Pungpungan Kecamatan Kalitidu Kabupaten Bojonegoro. MTs ini berdiri sejak tahun 1975. Akreditasi MTs Al Yakin adalah A. MTs Al Yakin merupakan lembaga pendidikan yang berada dibawah naungan Yayasan Pendidikan Islam Al Fattah (YASPIA).

Letak MTs Al Yakin berada di:

Sebelah utara $\quad$ : Jalan Raya
Sebelah Timur
Sebelah Selatan: Rumah Warga
Sebelah Barat

\section{Visi dan Misi MTs Al Yakin Pungpungan}

Visi

Terbentuknya lulusan yang menguasai IPTEK dan memiliki IMTAQ yang mantap, yang berwawasan Ahlussunnah Wal Jama'ah.

\section{Misi}

1) Melaksanakan pengembangan silabus

2) Melaksanakan inovasi dalam proses pembelajaran

${ }^{7}$ Sugiyono, Metode penelitian pendidikan: (pendekatan kuantitatif, kualitatif dan R \& D) (Bandung: Alfabeta, 2008), 105. 
3) Melaksanakan pengembangan standar kelulusan

4) Melaksanakan pengembangan SDM pendidik dan tenaga kependidikan

5) Melaksanakan pengembangan fasilitas sekolah

6) Melaksanakan pengembangan media pembelajaran

7) Melaksanakan pengembangan manajemen sekolah

8) Melaksanakan pengembangan penggalangan pembiayaan pendidikan yang memadai

9) Melaksanakan pengembangan kegiatan peningkatan mutu akademik dan non akademik

10) Mengembangkan potensi dan kreatifitas siswa melalui bidang kegiatan

11) Menumbuhkan penghayatan dan pengamalan ajaran agama islam yang berwawasan ahlussunnah wal jama'ah

\section{Tujuan MTs Al Yakin Pungpungan}

1) Mengembangkan silabus kelas 7-9 semua mapel atau mulok

2) Mengembangkan pembelajaran dengan metode yang tepat (CTL, belajar tuntas, kooperatif dsb)

3) Mengembangkan standar kelulusan'

4) Mengembangkan daya saing sekolah dengan membentuk kelas unggulan dan penambahan keagamaan

5) Memiliki standar pendidik dan tenaga kependidikan

6) Mengembangkan fasilitas sekolah, pada tahun 2012 sarana prasarana tercukupi

7) Mengembangkan media pembelajaran

8) Mengembangkan manajemen sekolah meliputi: kurikulum, kesiswaan, sarpras, humas dan administrasi.

9) Mengembangkan penggalangan pembiayaan pendidikan yang memadai

10) Mengembangkan kegiatan les atau tryout bagi kelas 9

11) Mengembangkan kegiatan privat khusus bagi kelas 7-8 yang berprestasi

12) Mengembangkan kegiatan ekstrakurikuler 
13) Mengembangkan kegiatan yang kreatif dan kompetitif untuk mengembangkan potensi peserta didik berlandaskan keimanan dan ketaqwaan yang berhaluan Ahlussunnah Wal jama'ah

14) Menumbuhkan penghayatan dan pengamalan ajaran islam yang berhaluan Ahlussunnah Wal jama'ah ${ }^{8}$.

\section{Guru dan Siswa}

Guru merupakan salah satu hal yang terpenting dalam proses kegiatan belajar mengajar. Karena dengan adanya guru, proses transfer ilmu akan berjalan. Guru yang ada di MTs Al Yakin Pungpungan berjumlah 22, yaitu:

\section{Gambar 1}

Keadaan Guru MTs Al Yakin Pungpungan

\begin{tabular}{lll}
\hline No & Nama & Jabatan \\
\hline $\mathbf{1}$ & Drs. Rosidi & Kasek \\
$\mathbf{2}$ & Dra. Rosi'in & Humas \\
$\mathbf{3}$ & Dwi Issadari, S. Pd & Wakur \\
$\mathbf{4}$ & Tolip, S. Pd & Wakasis \\
$\mathbf{5}$ & Luqman hakim, S. Pd. I & sarpras \\
$\mathbf{6}$ & Mashariraya, S. Pd. I & Guru \\
$\mathbf{7}$ & Siti Mudlikah, S. Pd. & Guru \\
$\mathbf{8}$ & H. Joko Suwito, S. Pd & Guru \\
$\mathbf{9}$ & Sri Wahyuni, S. Pd & Guru \\
$\mathbf{1 0}$ & Nur aini, S. Pd & Guru \\
$\mathbf{1 1}$ & Yayuk unsurni, S. Pd.I & Guru \\
$\mathbf{1 2}$ & Yayuk Sukraningsih, S. Pd & Guru \\
$\mathbf{1 3}$ & Suheri, S. Pd & Guru \\
$\mathbf{1 4}$ & Anas, M. Pd.I & Guru \\
$\mathbf{1 5}$ & Antok Wibowo, S. Pd & Guru \\
$\mathbf{1 6}$ & Wahyu Setiawan, S. Pd & Guru \\
$\mathbf{1 7}$ & Khayatun Nikmah, S. Psi & Guru \\
$\mathbf{1 8}$ & Istighosah, S. Pd.I & Guru \\
\hline
\end{tabular}

${ }^{8}$ Dokumen dari MTs Al Yakin Pungpungan 


\begin{tabular}{lll}
\hline 19 & Ida andriyani & Guru \\
$\mathbf{2 0}$ & Nur Solikin, S. Pd & Guru \\
$\mathbf{2 1}$ & Yaumil Jumatin & TU \\
$\mathbf{2 2}$ & Sutikno & TU \\
\hline
\end{tabular}

Sedangkan siswa MTs Al Yakin berasal dari beberapa desa, yaitu ada desa pilangsari, desa mayangrejo, desa mojosari, desa kandangan, desa srawun, desa ngujo, desa kumpul, desa Mojo, desa ngringinrejo, dan desa wadang serta desa pungpungan itu sendiri. Siswa MTs Al Yakin Pungpungan merupakan madrasah swasta yang memiliki siswa yang cukup dibandingkan dengan sekolahan swasta yang lainnya. Adapun jumlah Siswa keseluruhan Siswa MTs Al Yakin Terdiri dari 282 Siswa.

\section{Kurikulum}

Kurikulum merupakan kata yang berasal dari bahasa latin, yang memiliki makna tempat berpacu?. Kurikulum merupakan bagian yang terpenting dari unsur-unsur pembelajaran. Tanpa adanya sebuah kurikulum yang jelas maka tujuan pembelajaran juga tidak akan jelas. Kurikulum yang dilakukan dalam kegiatan pembelajaran yang ada di MTs Al Yakin Pungpungan menggunakan kurikulum K-13 sesuai yang disarankan dan dianjurkan oleh pemerintah. Kurikulum K-13 ini merupakan sejalan dengan kegiatan yang sudah dikerjakan dan diimplementasikan di MTs A Yakin Pungpungan.

\section{Evaluasi}

Evaluasi disini akan mengevaluasi pada penilaian atas perencanaan, penilaian atas pelaksanaan dan penilaian atas aktifitas yang udah diselesaikan dan dikerjakan. Sedangkan fungsi evaluasi merupakan untuk memberikan suatu informasi yang valid dan terpercaya. Kegiatan evaluasi yang dilaksanakan di MTs Al Yakin melalui kegiatan ulangan harian dan semester.

9 Abdul Majid, Belajar Dan Pembelajaran Pendidikan Agama Islam, 2nd ed. (Bandung: Remaja Rosdakarya, 2014), 34. 
Jadi diakhir semester akan ada evaluasi sebagai tolak ukur keberhasilan siswa dalam melaksanakan pembelajaran di kelas.

\section{Kegiatan Safari Dakwah}

\section{Pengertian Safari Dakwah}

Safari menurut kamus bahasa Indonesia memiliki arti perjalanan ${ }^{10}$. Didalam kamus al bisri kata safari berasal dari kata "safara" yang bearti pergi atau bepergian". Jadi bisa ditarik kesimpulan, bahwa safari merupakan perpindahan atau bepergian dari satu tempat ke tempat yang lain.

Kita semua tidak asing lagi mendengar kata-kata dakwah. Dakwah secara bahasa memiliki aarti (دعا - يدعو) yang artinya seruan atau ajakan. ${ }^{12}$

Adapun dakwah memiliki dua makna yaitu makna pembinaan dan pengembangan. Dakwah yang bermakna pembinaan yaitu suatu hal yang berupaya untuk menyempurnakan terhadap sesuatu yang sudah ada sebelumnya. Sedangkan dakwah yang memiliki arti pengembangan ialah suatu bentuk kegiatan yang dilakukan agar memperoleh sebuah hasil yang baru yang belum ada sebelumnya. ${ }^{13}$ Dakwah itu Suatu proses yang saling berkesinambungan yang dilakukan oleh sesorang (da'i) untuk mengubah atau mengajak seseorang ke jalan yang benar, yang sesuai dengan tuntunan Agama Islam. ${ }^{14}$ sebagaimana firman Allah SWT, Yang berbunyi:

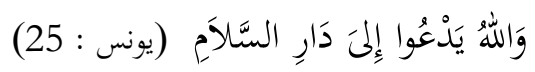

${ }^{10}$ Yus Badudu and Sutan Mohammad Zain, Kamus Umum Bahasa Indonesia, Cet. 1 (Jakarta: Pustaka Sinar Harapan, 1994), 1196.

${ }^{11}$ Bisri Adib, AL Bisri Kamus Indonesia- arab dan arab-Indonesia (Surabaya: Pustaka Progressif, 1999), 328.

${ }^{12}$ Sasono Adi, Solusi Islam Dan Problematika Umat (Ekonomi, Pendidikan Dan Dakwah) (Jakarta: Gema Insani Press, 1998), 150.

13 Enung Asmaya, Aa Gym Dai Sejuk Dalam Masyarakat Majemuk. (Jakarta: Mizan Publika, 2003), 28.

${ }^{14}$ Hafidhuddin, Dakwah Aktual, 1st ed. (Jakarta: Gema Insani Press, 1998), 77. 
Artinya: Allah Menyeru Manusia ke Darussalam (Surga). (QS. Yunus:25)

Tujuan dari dakwah sendiri adalah mengajak dan mengubah perilaku untuk melakukan dan menerima ajaran islam dan diterapkan dalam kehidupan sehari-hari.

Jadi safari dakwah merupakan suatu perjalanan atau tindakan yang dilakukan sesorang untuk merubah diri sendiri maupun orang lain untuk menjadi manusia yang sempurna, baik dihadapan manusia maupun dihadapan sang pencipta.

Safari dakwah yang dilaksanakan MTs Al Yakin pungpungan dengan menggunakan metode tour, dari rumah teman kerumah teman yang lainnya. Safari dakwah ini merupakan sebuah rangkaian kegiatan atau program OSIS MTs A Yakin. Awalnya sulit sekali untuk mengadakan safari dakwah ini, akan tetapi dengan berjalannya waktu, kegiatan safari dakwah ini bisa diterima oleh OSIS dan memiliki efek yang besar terhadap karakter siswa.

\section{Pelaksanaan Safari Dakwah}

Banyak sekali kegiatan ataupun program yang direncakan dan dicanangkan oleh Lembaga MTs Al Yakin Pungpungan. Salah satu kegiatan yang rutin dilaksanakan adalah safari dakwah MTs Al Yakin. Kegiatan safari dakwah OSIS MTs Al Yakin Pungpungan dilakukan setiap 2 minggu sekali pada pagi hari pukul 08.00-10.00 WIB. Tempat pelaksanaan kegiatan safari dakwah dilakukan bergantian dari rumah siswa kerumah siswa yang yang lainnya.

Menurut bapak Tolip, S. Pd ${ }^{15}$ selaku waka kesiswaan MTs Al Yakin mengungkapkan, bahwa Safari Dakwah merupakan kegiatan rutinan yang dilaksanakan oleh OSIS MTs Al Yakin pungpungan. Kegiatan ini merupakan sebuah ide tau gagasan dari kepala sekolah MTs Al Yakin pungpungan. Dengan adanya kegiatan safari dakwah diharapkan mampu membentuk mental siswa terutama dalam hal karakter atau perilaku siswa.

15 Wawancara dilaskanakan pada tanggal 6 desember 2017 pukul 09.00 WIB 
Adapun pelaksanaanya yang dilakukan dalam safari dakwah melalui beberapa tahap, yaitu: kegiatan persiapan atau pembagian, kegiatan Inti dan kegiatan Penutup.

\section{a) Persiapan}

Sebelum pelaksanaan safari dakwah, setiap siswa diberikan pembekalan untuk persiapan pelaksanaan kegiatan. Untuk kegiatan persiapan atau pembagian itu dilaksanakan 4 atau 5 hari yang dilaksanakan di MTs Al Yakin Pungpungan dengan seluruh OSIS serta kepala sekolah dan Pembina OSIS. Dalam persiapan ini Pembina OSIS dan Ketua OSIS membagi tugas masing-masing sekaligus menentukan lokasi kegiatan tersebut. Pembagian tugas ini akan bergilir dengan teman-temannya. Semua siswa akan mendapatkan bagiannya masing-masing sesuai jadwal yang sudah ditentukan. Dengan adanya pembagian seperti ini, siswa akan merasa adil dan bisa mempersiapkan diri untuk pelaksanaan. Selain itu juga, persiapan yang matang akan menghasilkan hasil yang memuaskan.

\section{b) Pelaksanaan Kegiatan}

Pelaksanaan kegiatan safari dakwah MTs A Yakin Pungpungan ini didalamnya ada beberapa rangkaian acara kegiatan yaitu pembukaan, pembacaan Asmaul husana dan yasin, pembacaan Ratibul haddad, pembacaan Maulidud didaba' dan ceramah agama. Sebagaimana dijelaskan dibawah ini:

\section{1) Pembacaan asmaul husna dan Yasin}

Dalam kegiatan safari dakwah, proses Pembacaan asmaul busna dan yasin dilantunkan dan dibacakan oleh OSIS dan diikuti OSIS yang lainnya. Dengan pembacaan asmaul busna dan Yasin serentak akan menimbulkan kekompakan dalam kegiatan tersebut. Selain itu, asmaul husna dan yasin mampu membuat hati semakin dingin dan dekat kepada Allah SW'T. 
Dalam wawancara dengan pak mashariraya ${ }^{16}$, kegiatan rutinan pembacaan pembacaan asmaul busna dan yasinan merupakan salah satu kegiatan atau amalan yang dilakukan oleh sebagai salah satu dakwah Islam ${ }^{17}$. Kegiatan Pembacaan Asmaul husna dan Yasin merupakan suatu hal yang luar biasa dalam pembentukan karakter OSIS MTs Al Yakin pungpungan. Karena masih tataran MTs atau SMP sudah diberikan sebuah amalan atau kebiasaan yang mendukung untuk masa depannya. Akan tetapi, dalam hal pembentukan karakter bagi OSIS MTs Al Yakin harus tetap menjaga komunikasi dengan keluarga dan masyarakat sekitar. Karena mereka merupakan salah satu faktor pendukung dalam pembentukan karakter. Sehingga tidak ada kesalahfahaman diantara masingmasing pihak.

\section{2) Pembacaan Rotibul haddad}

Dinamakan Rattibul haddad karena pengarang dan penyusunnya ialah $\mathrm{Al}$ habib Abdullah bin Alwi bin Muhammad a haddad, beliau merupakan Ulama besar di abad ke-11 $\mathrm{H}$ atau abad Ke-17 M. Beliau lahir di kota Tarim, Hadhramaut, Yaman.Tepatnya beliau lahir pada tanggal 5 Shafar 1044 H. Rattibul hadda disini merupakan salah satu amalan yang sering dilakukan oleh kelauarga besar Yayasan pendidikan Islam A Fattah, termasuk MTs Al Yakin yang didalamnya. Karena didalamnya terdapat susunan atau urutan yang Biasanya digunakan untuk menamakan bacaan-bacaan (dzikrullah) atau doa-doa. Tujuan Yayasan mengamalkan ini selain untuk amalan pribadi yang

16 Guru Bahasa arab dan aq- Qur'an hadist di MTs Al Yakin Pungpungan, beliau merupakan salah satu guru yang teladan dan aktif dalam hal keagamaan. Ia termasuk salah satu murid mbah maemun zubaer sarang rembang. Selain lulusan Pendidikan Agama Islam beliau juga memiliki ijzah Pendidikan Bahasa Inggris

${ }^{17}$ Wawancara dilaksanakan pada tanggal 6 Desember 2017, pukul 09.30 WIB 
paling utama adalah mengumpulkan keluarga besar sebagai kekompakan dan kekeluargaan. Oleh karena itu, setiap kegiatan yang dilaksanakan harus diikuti dan ada pembacaan ratibul haddad. Begitupun juga dalam safari dakwah, pembacaan rattibul haddad disini juga selu dikumandangkan dan dibacakan pada saat kegiatan tersebut. Dengan harapan kemantaban dan keimanan dari OSIS MTs Al Yakin semakin kuat dan meningkat.

\section{3) Pembacaan Berzanji}

Ketika wawancara dengan pak Mustain Faqih ${ }^{18}$, menerangkan bahwa Pembacaan berzanji merupakan salah satu kegiatan yang sering dilakukan dan dikerjakan oleh umat Islam terutama kaum nahdiyyin. Pada kegiatan safari dakwah disini juga tidak terlepas akan adanya pembacaan berzanji sebagai rangkain kegiatan tersebut. Esensi dari pembacaan berzanji tersebut sebagai salah satu tujuan untuk penyegaran terhadap tokoh yang fenomena diajaran Islam yaitu Nabi Muhammad SAW. Selain itu juga, beliau merupakan sebagai inspirator dan motivator dikalangan umat Islam. dengan harapan seperti itu OSIS MTs Al yakin Pungpungan mampu menerapkan dan mengimplementasikan apa yang pernah diajarkan sang inspirator dan sang motivator tersebut, baik mengikuti ucapan, tingkah laku atau ketetapnnya.

\section{4) Ceramah Agama}

Ceramah Agama disini pembicaranya berasal dari siswa itu sendiri. Salah satu kegiatan ceramah agama ini adalah untuk membentuk sikap keberanian seorang OSIS yang ada di MTs Al Yakin Pungpungan. Dengan adanya Ceramah agama siswa akan memiliki sikap tanggungjawab terhadap tugas yang diembannya.

18 Guru Aswaja MTs Al Yakin Pungpungan, wawancara dilaksanakan pada tanggal 6 desember 2017 Pukul 11.15 WIB. 
Selain bertanggungjawab sebagai pembicara, seorang siswa dituntut dan berusaha bersikap toleransi dan bersikap adil terhadap semuanya. Ceramah agama ini merupakan sebagai salah satu tombak untuk pembentukan karakter yang ada didalam diri OSIS MTs AL Yakin Pungpungan. Disi lain, dalam kegiatan seperti ini akan menumbuhkan sebuah keimanan, ketakwaan, meningkatkan mental dan yang paling utama adalah dalam pembentukan karakter bagi OSIS MTs Al Yakin Pungpungan. Karena yang akan dihadapi ketika dimasyarakat ada beberapa macam golongan.

Kesemuanya rangkaian tersebut merupakan salah satu untuk membentengi perilaku dan pembentuk OSIS MTs Al Yakin di "zaman Now". Selain itu hal yang utama kegiatan ini adalah sebagai pembentuk karakter bagi OSIS MTs Al Yakin Pungpungan agar memiliki keimanan dan ketaqwaan yang kuat.

\section{c) Evaluasi}

Evaluasi dalam pelaksanaan safari dakwah dilaksanakan ketika sudah selesai dalam kegiatan tersebut. Evaluasi ini dilaksanakan untuk menilai dan membenarkan seluruh Osis MTS Al Yakin Pungpungan kalau ada kekurangan dan kesalahan. Dengan harapan kegiatan selanjutnya akan memberikan sajian yang lebih baik lagi.

Kegiatan safari dakwah OSIS MTs Al Yakin pungpungan ini tidak dilepaskan begitu saja. Akan tetapi kepala sekolah dan waka kesiswaan dan ditemani beberapa guru MTs $\mathrm{Al}$ yakin juga ikut andil untuk melakukan pendampingan terhadap OSIS MTs Al Yakin. Tujuannya adanya pendampingan ialah sebagai salah satu bentuk supervisor sekaligus meyakinkan kepada OSIS MTs Al yakin dalam pelaksanaan kegiatan safari dakwah. Dengan adanya supervisor, kegiatan tersebut akan berjalan dengan baik dan lancar. 


\section{A. Nilai Karakter Yang Tampak dalam Kegiatan Safari Dakwah OSIS MTs Al Yakin}

Safari dakwah sebagai bentuk program kegiatan MTs Al Yakin pungpungan sangat membantu dan menjadikan serta mengeluarkan bakat dan minat serta membentuk sebuah karakter bagi OSIS MTs Al Yakin Pungpungan. Pendidikan karakter merupakan sebagai misi pertama dari delapan misi sebagai wujud visi pembangunan nasional.

Peningkatan dan perkembangan dalam pembentukan karakter dapat dilihat ketika OSIS mampu menyampaikan amanat atau pesan dalam sebuah kegiatan. Harus disadari bahwa dalam penyampaian sebuah pesan dan sebuah tindakan yang dikerjakan merupakan tolak ukur dalam proses pembentukan karakter. Salah satu yang dikerjakan ialah dengan adanya safari dakwah. Dengan terlaksananya safari dakwah menyimpulkan bahwa safari dakwah memiliki beberapa aspek atau pengaruh terhadap karakter yang dimilikinya, yaitu:

1. Religius

Dari rangkaian safari dakwah tersebut mampu membentuk, meningkatkan dan mengembangkan karakter religius. Dengan membaca yasin, membaca asmaul husna, Maulid diba', membaca ratibul haddad serta ceramah agama memberikan kekuatan yang kuat. Dengan harapan keimanan dan ketwakwaan yang dimiliki oleh OSIS MTs Al Yakin pungpungan semakin meningkat. dengan begitu sikap, perilaku dan karakter OSIS MTs Al yakin akan menjadi lebih baik dari pada sebelumnya. Serta memberikan efek terhadap siswa yang lainnya.

2. Kejujuran

Karakter yang terlihat dari kegiatan safari dakwah tersebut adalah kejujuran. Kejujuran ini tampak ketika OSIS diberikan kegiatan dikerjakan dan dilaksanakan dengan sungguh-sungguh tanpa ada kecurangan. Kejujuran juga bisa dilihat dan tampak dari pembacaan asmaul busna, Yasin, Maulid Diba' dan membaca 
ratibul haddad yang dibaca secara urut dan dilaksanakan secara seksama. Tidak ada satupun OSIS yang membaca dengan cepat, terlalu cepat bahkan selesai duluan.

3. Disiplin

Sikap karakter yang tumbuh dan berkembang serta memiliki efek dari kegiatan safari dakwah ialah disiplin dan semangat. Kedisiplinan yang tampak dari sini ialah ketika kedatangan dengan tepat waktu dan perlengkapan yang dibawa sesuai dengan persiapan yang ditentukan. Selain itu, ketika dalam pelasakanaan safari dakwah OSIS MTs Al Yakin mengikuti dengan seksama dan tidak berbicara sendiri dengan temannya. Bahkan OSIS MTs A yakin sangat antusias sekali dalam kegiatan tersebut. Darisinilah bisa dilihat bahwasannya Safari dakwah memiliki efek bagi Osis MTs Al Yakin Pungpungan.

4. Semangat

Semangat yang ditimbul dari kegiatan safari dakwah ini ialah semangat untuk selalu berjuang dan menuntut ilmu meskipun berada diluar sekolah. Semangat seperti inilah yang seharusnya ditumbuhkan bagi siswa-siswa yang lainya. Selain itu juga, ketika berada di luar kegiatan safari dakwah banyak OSIS yang selalu semangat dan mengamalkan amalan-amalan tersebut baik ketika habis shalat magrib dan isya'. Dengan semangat yang seperti ini, diharapkan semua kegiatan juga bisa dikerjakan dengan penuh semangat.

5. Mandiri dan Tanggungjawab

Safari dakwah disini memiliki efek berupa Tanggungjawab. Dari OSIS MTs Al Yakin diberikan tugas dan tanggungjawab sebagai pelaksana dikerjakan dengan baik dan sungguh-sungguh sesuai dengan tugasnya masing-masing. Tidak ada OSIS yang mengundurkan diri dan bolos ketika pealaksanaan safari dakwah, kecuali bagi Siswa OSIS yang sakit. Selain itu juga mampu memberikan karakter mandiri yang tidak memberikan beban atau melimpahkan tugasnya kepada temannya. Dengan demikian kemandirian yang ada di dalam diri akan tercipta dengan sendirinya. 


\section{Kesimpulan}

Kegiatan Safari Dakwah merupakan serangkaian kegiatan yang disiapkan untuk membekali anggota OSIS agar memiliki karakter yang baik. Antara lain ialah sikap religius, kejujuran, disiplin, semangat, mandiri, tanggung jawab dan lainlain. Kegiatan ini tidak dilepaskan begitu saja, Akan tetapi dalam pengawasan kepala sekolah, waka kesiswaan dan ditemani beberapa guru MTs Al yakin yang mana juga ikut andil untuk melakukan pendampingan terhadap OSIS MTs Al Yakin. Tujuan adanya pendampingan ialah sebagai salah satu bentuk supervisor sekaligus meyakinkan kepada OSIS MTs Al yakin dalam pelaksanaan kegiatan safari dakwah. Dengan adanya supervisor, kegiatan tersebut diharapkan berjalan dengan baik dan lancar.

Dengan adanya Safari Dakwah melatih anggota OSIS agar memiliki keberanian. Dalam hal ini berani pada hal positif, misalnya berani berbicara di depan teman yang lain, berani bersosialisasi, dan bagaimana belajar berorganisasi yang baik. Semua karakter tersebut harus dilatih dan dibiasakan sejak dini agar kelak mereka terbiasa. Melalui kegiatan seperti ini merupakan suatu wadah yang efisien untuk penanaman karakter baik seperti harapan kita bersama. Selain itu melatih sikap tanggungjawab. Tugas yang diberikan oleh pembina dikerjakan dengan baik dan penuh tanggungjawab. Tidak ada OSIS yang mengundurkan diri dan bolos ketika pealaksanaan safari dakwah, kecuali bagi Siswa OSIS yang sakit. Selain itu juga melatih sikap kemandirian, semua tugas dilaksanakan dengan baik tidak ada yang dilimpahkan kepada siswa lain. Dengan demikian kemandirian yang ada di dalam diri akan tercipta dengan sendirinya. 


\section{Referensi}

Adi, Sasono. Solusi Islam Dan Problematika Umat ( Ekonomi, Pendidikan Dan Dakwab). Jakarta: Gema Insani Press, 1998.

Adib, Bisri. AL Bisri Kamus Indonesia- arab dan arab -Indonesia. Surabaya: Pustaka Progressif, 1999.

Asmaya, Enung. Aa Gym Dai Sejuk Dalam Masyarakat Majemuk. Jakarta: Mizan Publika, 2003.

Badudu, Yus, and Sutan Mohammad Zain. Kamus Umum Bahasa Indonesia. Cet. 1. Jakarta: Pustaka Sinar Harapan, 1994.

Faiq Jauharu, Huda. 'Nilai-Nilai Pendidikan Akhlak Menurut Al Qur'an Surat at Thagabun Ayat 14'. IAIN Walisongo, 2018.

Hafidhuddin. Dakwah Aktual. 1st ed. Jakarta: Gema Insani Press, 1998. Koesoema A., Doni. Pendidikan Karakter. Jakarta: Gramedia Widiasarana Indonesia, 2007.

Ma`arif, Muhammad Anas. 'Analisis Strategi Pendidikan Karakter Melalui Hukuman Preventif. Ta'allum: Jurnal Pendidikan Islam 6, no. 1 (6 March 2018): $31-56$. https://doi.org/10.21274/taalum.2018.6.1.31-56.

Majid, Abdul. Belajar Dan Pembelajaran Pendidikan Agama Islam. 2nd ed. Bandung: Remaja Rosdakarya, 2014.

Rosidatun. Model implemntasi pendidikan karakter. Gresik: Caramedia Commucication, 2018.

Sugiyono. Metode penelitian pendidikan: (pendekatan kuantitatif, kualitatif dan $\mathrm{R} \ll D)$. Bandung: Alfabeta, 2008.

Yusuf, Syamsu. Landasan Bimbingan Dan Konseling. Bandung: Remaja Rosdakarya, n.d.

Wawancara dilaksanakan pada tanggal 6 Desember 2017, pukul 09.30 WIB

Wawancara dilaskanakan pada tanggal 6 desember 2017 pukul 09.00 WIB

Dokumen dari MTs Al Yakin Pungpungan

Guru Aswaja MTs Al Yakin Pungpungan, wawancara dilaksanakan pada tanggal 6 desember 2017 Pukul 11.15 WIB. 